\title{
SOME CORTICAL ASSOCIATION SYSTEMS RELATED TO AUDITORY FUNCTIONS
}

\author{
EDITH MAOLENNAN HURST ${ }^{1}$ \\ Department of Anatomy, University of Michigan, Ann Arbor ${ }^{2}$
}

NINE FIGURES

\section{INTRODUCTION}

Many observers have considered the peripheral and central portions of the auditory pathways. In the present paper the central connections only, chiefly those of cortical association regions, will be considered. In reference to cortical areas, the nomenclature of Brodmann ('09) is used in all cases.

A part of the interest in the auditory system has arisen from the clinical pictures presented in cases of human auditory deficiency. Those resulting from certain cortical lesions which involve auditory association cortex have been particularly striking because, although the patient is not deaf as the result of such a lesion, he is unable to understand spoken language or the meaning of sounds. The various studies of the auditory projection and association cortices have led to the conclusions that the human auditory projection area is located in areas 41 and 42 and that in this region sounds are recognized as being of a certain pitch. However, area 22 which surrounds the projection area is thought to be the region where sounds become meaningful. This part of the cortex, therefore, is referred to as an "auditory association area." Studies of human auditory aphasia have been con-

${ }^{1}$ A dissertation submitted in partial fulfillment of the requirements for the degree of Doctor of Philosophy in the University of Michigan. 1956.

${ }^{2}$ Present address is Anatomy Department, Hahnemann Medical College, Philadelphia 2, Pennsylvania. 
ducted by Nielsen ('46), and the whole problem in reference to man has been well summarized in his work.

\section{LITERATURE}

Auditory connections have been studied in mammals other than man at the brain stem level by Barnes, Magoun and Ranson ('43), who made lesions in the medulla of the monkey, Macaca mulatta, and traced degenerated fibers rostrally, and by Thurlow, Gross, Kemp and Lowy ('51), who placed microelectrodes in the inferior colliculus of the cat and recorded responses to peripheral stimuli. Kemp and Coppée ('36) also conducted studies on brain stem auditory pathways. Poliak ('32) and Walker ('38) have carried out detailed anatomical experiments in order to determine the relationships of the auditory regions of the thalamus and the cerebral cortex in primates. Yoshida ('24) and Tunturi ('44, '45, and '46) studied similar relationships in the dog and Waller in the rat ('34) and in the cat ('40). The phylogenetic aspects of the problem have been reviewed by Ades and Felder ('45) and by Poliak ('32), but their studies have been concerned primarily with thalamocortical connections in mammals.

Cortical relations of the auditory projection and association cortices have been studied by Bailey, von Bonin, Davis, Garol, and McCulloch ('44) and by Lemmen ('51) from an anatomical point of view. Ades and Brookhart ('50), Ades and Felder ('42a and '42b), Licklider and Kryter ('42) and Walzl and Woolsey ('43) have approached the problem from an electrophysiological standpoint.

The experiments carried out in the course of the present work have been done to study the thalamocortical auditory projection and the efferent connections of the auditory projection area and auditory association area. The regions which received these connections were, in turn, examined to discover their efferent systems. Thus, pathways which are traveled by impulses initiated by auditory stimuli can be traced, and the anatomical relations between the auditory association areas and cortical areas of different significance can be determined. 
The author wishes to express her deep appreciation to Dr. Elizabeth C. Crosby for her guidance and suggestions during the course of this work and the writing of this paper.

\section{MATERIALS AND METHODS}

This series of experiments was confined to two species of the macaque monkey, Macaca mulatta and Macaca irus (cynamolgus). ${ }^{3}$ The weights of the animals varied from $0.9 \mathrm{~kg}$ to $5.0 \mathrm{~kg}$, and each monkey appeared to be healthy upon both preoperative and postoperative testing.

Experimental lesions were placed in the brain of each animal by ablation with a surgical aspirator, scalpel or cotton pledget; or the Lab-Tronics stereotaxic instrument was utilized in the placing of lesions. The anesthetic employed was diethyl ether or Pentothal Sodium (Abbott). A craniotomy was performed, and the dura was reflected to expose the brain in each case. After the operative procedure had been carried out under sterile conditions, the incised tissues were sutured into place, and the monkey was allowed to recover.

The animal was observed for any postoperative changes in behavior and, after a period of two weeks following the last operation, was sacrificed. The nervous tissue was fixed by perfusion with a $10 \%$ solution of formalin and was processed according to the Swank and Davenport ('35) modification of the Marchi technique or by the Huber-Guild pyridine-silver method (Huber and Guild, '13). Conclusions as to the courses of certain pathways were then drawn from the study of the degenerated fibers present in the material as a result of the lesions.

\section{EXPERIMENTAL PROCEDURE}

Sixteen monkeys were utilized in this series of experiments, and 21 operations in all were performed. Some of the opera-

s To the Walter C. Hill Research Fund, which provided technical assistance, and to Parke, Davis and Company, Detroit, Michigan, who provided the animals for this research program, the writer is greatly indebted. 
tions were merely confirmatory. Several attempts at destroying the medial geniculate nucleus with the stereotaxic instrument were unsuccessful because of variability in size of the monkeys, so the nucleus was removed by direct approach. The following protocols were selected as showing the more useful results obtained.

\section{Monkey 1}

The experimental animal, a Macaca irus (cynamolgus), was utilized in order to study the efferent connections of area 22 . On July 7 , 1953 area 22 was removed on the left, and a similar procedure was carried out on the right on July 15, 1953. The animal was sacrificed on July 29, 1953.

Upon microscopic examination of the material, the degenerated fibers were seen to extend from the sites of the lesions into the adjacent white matter and, thus, into the external capsule and the extreme capsule of the homolateral side. From each external capsule degenerated fibers could be traced into the corpus callosum but could not be differentiated farther because of an intermingling of similar degenerated fascicles from the contralateral area. Degenerated fibers also extended from the external capsule of each side into the homolateral inferior temporal area anterior to the lesion and into the cingulate gyrus. The extreme capsule carried degenerated fibers which appeared to end, on the side of their origin, in the superior and inferior frontal areas, the parietal area, the island, and the occipitotemporal area. There was no visible degeneration in the anterior commissure.

\section{Monkey 2}

A Macaca mulatta was used for the removal of areas 41 and 42. On June 24, 1954 the areas on the left side were ablated. On July 22, 1954 the animal was sacrificed.

Microscopic examination of the brain revealed that degenerated fibers extended from areas 41 and 42 to the adjacent, homolateral area 22. No other area of degeneration was visible.

\section{Monkey 3}

The experimental animal was a Macaca mulatta weighing about $5.0 \mathrm{~kg}$ and, therefore, of adult size. The first operation was carried out on October 15, 1954 to remove the occipitotemporal area on the left. The second operation was done on October 29, 1954 at which 
time an attempt was made to remove the tip of the temporal lobe, area 37 , on the right. On November 16, 1954 the monkey was sacrificed, and examination of the gross brain revealed that the lesion on the right was in the frontal operculum and not in the temporal pole. This operation was repeated on monkey 4. A photograph was taken (fig. 1) of the lesion in the temporo-occipital region of monkey 3.

Microscopic examination of the occipitotemporal lesion on the left revealed that degenerated fibers extended from the site of the lesion (fig. 2) to a position surrounding the posterior horn of the lateral ventricle (fig. 3 ). They continued posteriorly (fig. 4) in this position to the occipital area. Degenerated fibers also appeared in the homolateral medial longitudinal fasciculus and in the superior colliculus.

\section{Monkey 4}

This animal was a Macaca mulatta in which the temporal pole, area 37 , was removed. The operative procedure was performed on December 3, 1954. The animal was sacrificed on December 20, 1954.

Upon microscopic examination it was found that degenerated fibers extended from the site of the lesion into the white matter of the temporal pole and, from there, into the homolateral putamen and globus pallidus.

\section{Monkey 5}

A Macaca mulatta was utilized to demonstrate the efferent paths originating in the island. The first operative procedure was carried out on January 7,1955 , and the left parietal operculum was removed in order to approach the island. The lesion was placed by the use of a scalpel. A second experiment was begun on the right side, but it was not completed because of an apparent dural adhesion in the parietal cortex.

The animal was sacrificed on January 31,1955 , and examination of the gross brain revealed that the lesion was not deep enough and involved the operculum only and not the island; therefore, the brain was not processed further.

\section{Monkey 6}

Since in the preceding experiment the lesion was not deep enough, attempts were made to remove the insular tissue bilaterally. In this monkey a somewhat different approach to the desired field was used than that which was employed in monkey 5 . The first operation was carried out on March 11, 1955. The operculum of the left hemisphere was retracted so that the island was in view; then the insular tissue 
was aspirated. On March 25, 1955 the island was removed from the right hemisphere by a similar procedure. The animal was sacrificed on April 7, 1955 .

Examination of the material microscopically revealed degenerated fibers in the putamen of each side and in the corpus callosum. Degenerated fibers were also present in the external capsule and in the extreme capsule and extended from these areas into the amygdala.

\section{Monkey 7}

The following operation was done to examine the course of the cortical projection system of the medial geniculate nucleus as indicated by the degenerated fibers after removal of the nucleus. Since attempts to remove the nucleus with the stereotaxic equipment had failed because of the inability to obtain monkeys of a standard size, it was decided to place the lesion in the brain of a Macaca mulatta by ablation with the surgical aspirator. The medial geniculate nucleus of the dorsal thalamus is in a position in the monkey brain which is impossible to reach without removing a great deal of cerebral cortex. Most of the temporal lobe had to spared since part of it contained the projection fibers from the medial geniculate nucleus.

The left occipital lobe, the posterosuperior part of the temporal lobe, and as much of the left parietal and frontal lobes as was necessary to bring the medial geniculate nucleus into view, were removed. It was realized, of course, that such a procedure would cause a contralateral homonymous hemianopsia because of removal of the visual projection area on the occipital cortex. It would produce some sensory loss and partial motor paralysis of the contralateral limbs because of destruetion of portions of the sensory and motor areas on the parietal and frontal cortices, respectively. However, none of these lesions should affect the auditory projection system, which was of prime importance in the experiment.

The operative procedure was performed on July 8,1955 on the left side, and the medial geniculate nucleus was removed according to the method outlined. As soon as the animal became active it was obvious that, as was to be expected, he had a hemiplegia on the right side of the body, particularly pronounced in the upper extremity. However, this hemiplegia gradually became less noticeable over the extent of the observation period, and the animal had very little difficulty with the lower extremity by the end of the two weeks of observation. At this time the upper limb could be used for carrying out gross movements. It was very difficult to demonstrate the contra- 
lateral homonymous hemianopsia since the animal moved its head as a compensatory action for the loss of the visual field. In spite of the fact that about one-fourth of the cerebral cortex had been removed, the animal was able to behave much as it had preoperatively except in the carrying out of finer movements in the right upper extremity.

On July 22, 1955 the animal was sacrificed, and the gross brain was photographed on November 10, 1955 (fig. 7). Microscopic examination of the sections revealed that the left medial geniculate nucleus had been removed without destruction of the underlying tegmentum and that degenerated fibers extended from the nuelus to the superior temporal gyrus of the homolateral side. The fibers could be seen above the lateral geniculate nucleus (fig. 8), deep in the superior temporal gyrus and near the surface of the gyrus.

\section{Monkey 8}

A Macaca mulatta was used to study the cortical projection system extending from the medial geniculate nucleus to the cerebral cortex. The experiment was carried out by the method of ablation for the same reasons as stated for the experiment done on monkey 7 and as a documentation of the previous experiment. On December 6, 1955 the left occipital lobe, the posterosuperior part of the left temporal lobe, and a portion of the left parietal and frontal lobes were removed, thereby exposing the left medial geniculate nucleus. Hemorrhage was controlled by the electrocautery, and the nucleus was removed by means of a surgical aspirator.

When the animal recovered from the effects of the anaesthetic the most readily observable deficit was a partial right hemiplegia. On December 8 the hemiplegia was much lessened. By December 15 it was no longer observable in the lower extremity, and the right arm was used at times. On December 21 the upper limb still showed a little paralysis but was used almost constantly. The contralateral homonymous hemianopsia and partial general sensory loss, which must have been present, could not be noticed by observing the animal as it carried on its normal activities. By the time the animal was sacrificed no deficit could be seen by casual observation of the animal although, as was true in monkey 7 , about one-fourth of the cerebral cortex had been removed.

The specimen was saerificed on December 22, 1955, and the brain was processed according to the Huber-Guild pyridine-silver technique. Microscopic examination of the material revealed that degenerated fibers extended from the medial geniculate nucleus to the 
homolateral superior temporal region in the same manner as did the degenerated fibers in monkey 7 .

\section{Monkey 9}

A Macaca mulatta was utilized to demonstrate efferent connections of area 22. On May 16, 1956 area 22 was ablated on the left side (fig. 9). The animal was sacrificed on June 13, 1956.

Microscopic examination of the brain confirmed the information obtained from the experiments carried out on monkey 1 . Degenerated fibers were seen to be present in the corpus callosum, the frontal and parietal cortices, the island and the occipio-temporal region.

\section{Monkey 10}

The tip of the temporal lobe, area 37, was removed from the left side of the brain of a Macaca mulatta on May 23, 1956. The animal was sacrificed on June 13, 1956.

Upon microscopic examination degenerated fibers were traced from the site of the lesion into the homolateral putamen and globus pallidus. These observations confirmed those made on the material from monkey 4.

\section{DISCUSSION}

Two of the experiments of the preceding series were carried out at the thalamic level; the others were performed on the cerebral cortex. Data in the literature from the studies of Poliak ('32), Walker ('38) and Licklider and Kryter ('42) indicate that the medial geniculate nucleus projects to areas 41 and 42 of the homolateral superior temporal convolution. In the present series of experiments the medial geniculate nucleus was removed by ablation (monkeys 7 and 8 ) in order to have first hand information regarding the exact area of termination of such projection fibers. It was interesting that, although they had been deprived of nearly one-fourth of their cerebral cortex, the animals in which the nucleus was removed by ablation appeared to be almost normal except for loss of finer movements of the contralateral hand and a contralateral homonymous hemianopsia.

The auditory projection area, as documented by these experiments, was the same as that recognized by Sugar, French 
and Chusid ('48) who conducted a series of experiments using auditory stimuli peripherally and the cathode ray oscilloscope technique centrally. Strychnine neuronography was then used to determine the efferent connections of the auditory projection area, and it was found that the auditory cortex of Macaca mulatta fired onto the lateral surface of the homolateral temporal lobe including area 22. Other areas such as $19,8,39$ and 37 also showed activity. However, according to Bailey, von Bonin, Garol and McCulloch ('43), who used strychnine neuronography with Macaca mulatta, strychninization of the primary auditory area caused firing into area 22 only. The removal of the auditory projection area (monkey 2 ) in our experiment caused degeneration in the adjacent area 22 only, thus, being in agreement with the results of Bailey, von Bonin, Garol and McCulloch ('43). The connection to area 22 is probably a direct one-neuron pathway, and it is within this area in man that impulses set up by auditory stimuli are integrated. In this region the impulses are not merely recognized as sounds of a certain pitch but are interpreted in terms of previous auditory experience and become meaningful. The functional relationships of these areas have not as yet been clearly demonstrated in Macaca mulatta; presumably they are, in general, similar to those in man.

Connections from the auditory projection area to the auditory association area having been reaffirmed, the latter area (area 22) was then ablated in monkeys 1 and 9 to examine its efferent connections. The lesions, which were placed bilaterally in these monkeys, extended over a large part of each area. Degenerated fibers could be traced into both the external capsule and the extreme capsule and from the latter into the island. From both of the capsules degenerated fibers entered the inferior frontal gyrus and, from the external capsule, the superior frontal (area 8) and cingulate gyri. Inferiorly, the amygdala contained degenerated fibers as did the tip of the temporal lobe anteriorly. The occipitotemporal area showed degenerated fibers also. Again, this material presents documentation for paths predicted on the basis of neuronography. 
Employing the method of strychnine neuronography, Petr, Holden and Jirout ('49) stimulated the lateral surface of the superior temporal convolution adjacent to the primary auditory area. They found that neurons from this region fired into the inferior frontal area, into the anterior, inferior parietal area and into the temporal region surrounding area 22. However, Hirasawa, Okano and Kamio ('38) and Lemmen ('51) demonstrated efferent connections to several regions including the basal ganglia, the pons, the midbrain and the medulla. Sunderland ('39) also made a localized lesion in area 22 of the macaque, Macaca sp., and found degenerated projection fibers present in the pons and in the medulla.

These cortical connections of area 22 are indicative of certain functional relationships. The island has been described as a second motor area (Frontera, '56), and connections to this region from area 22 may conduct impulses which cause the automatic turning of the extremities, head and eyes in the direction of auditory stimuli. The association pathway, demonstrated in our material between the auditory association area and area 8 , is concerned with voluntary turning of the eyes in the direction of a sound. The most specific voluntary eye movements are elicitable from area 8 (Crosby, '53). This is the area from which Sugar, French and Chusid ('48) recorded activity upon strychninization of the primary auditory area.

The significance of the connection of area 22 with the cingulate gyrus is not very obvious. Although the functions of the gyrus have not as yet been thoroughly studied, it is known to be connected with the hypothalamus, largely through the dorsal thalamus, and is often said to be a part of a pathway concerned with emotional expression and with regulation of the autonomic nervous system (Ward, '48). Since sounds affect emotional expression, this pathway may be utilized in modifying such expression. Connections from area 22 to the inferior frontal gyrus are important because the latter is a nodal point in the ares related to articulate speech.

In man the tip of the temporal lobe receives impulses from the olfactory and visual association areas as well as from the 
auditory association area. Lesions of the region may cause hallucinations involving these modalities. Baldwin, Frost and Wood ('54) in man, and Schneider and Crosby ('54) in the macaque were able to demonstrate a second motor area giving ipsilateral face movements, upon stimulation of the tip and rostral end of the temporal lobe. Thus, another efferent pathway is present in a region which receives connections from the auditory association area as well as from other association areas.

The parietal area just above the lateral fissure also shows degenerated fibers after destruction of area 22. The parietal region, too, is a second motor area (Peele, '44; Fleming and Crosby, '55).

The occipitotemporal area, in which degenerated fibers also end after ablation of area 22, is regarded as receiving fascicles from the visual association area, a connection demonstrated by Chusid, Sugar and French ('48). A descending system, the corticotegmental tract, arising in area 22 ends at the level of the superior colliculus about the cells of origin of a tegmentospinal tract and on the crainial nerve motor nuclei so that head and body can take part in coordinated movements (Lemmen, '51). These relations make possible the turning of the head and body in response to correlated visual and auditory stimuli.

Some regions which received pathways from the auditory association area were subsequently destroyed in order to study their efferent systems. In the animal (monkey 3) in which the occipitotemporal area was ablated, degenerated fibers were followed caudalward into preoccipital and occipital areas. It is known that fibers extend from the preoccipital area into this occipitotemporal region and from the occipital area into the preoccipital area and that they serve in some cases to increase, in others to suppress, the eye-movement responses (McCulloch, '49). Such a reciprocal relation is often seen in the central nervous system; it is thought that the functions of some of the fibers going caudalward into preoccipital and 
occipital areas may be that of reinforcement or of suppression of the efferent systems.

The island was ablated in monkey 6 , and degenerated fibers were traced to the putamen, corpus callosum and amygdala. The projection to the putamen is important because a second motor area has been identified on the lower half of the island by Frontera ('56), but the efferent connections of this second motor area have not been published. The results reported here suggest that this area discharges, in part at least, through the putamen.

Area 37, which is located on the tip of the temporal lobe, was destroyed in monkeys 4 and 10. Degenerated fibers were followed into the globus pallidus and the putamen, as would be expected since a second motor area in this region has been described by Schneider and Crosby ('54).

\section{SUMMARY}

1. Sixteen monkeys of the species Macaca mulatta and Macaca irus (cynomolgus) were used to study certain cortical association systems related to auditory functions. Twenty-one operations were performed. Lesions were placed in appropriate portions of the dorsal thalamus and the cerebral cortex. The animals were permitted to survive a suitable time, then sacrificed. The brains were prepared by the Swank-Davenport modification of the Marchi technique or by the Huber-Guild pyridine-silver method.

2. Study of the lesions involving the medial geniculate nucleus revealed degenerated fibers extending from this nucleus to the superior surface of the homolateral superior temporal convolution where areas 41 and 42 are located.

3. Marchi material prepared from brains with cortical lesions of areas 41 and 42 demonstrated efferent connections from these areas to area 22.

4. Following destruction of area 22, fascicles were traced into the frontal and parietal cortices, to the tip of the temporal lobe, to the island, to the occipitotemporal region and to the 
cingulate gyrus. The island was shown to project to the putamen; the temporal pole gave rise to efferent fibers extending into the putamen and the globus pallidus. The occipitotemporal area had efferent connections into the occipital region of the brain and projection fibers which could be traced into the superior colliculus and to the medial longitudinal fasciculus.

5. The experimental results were correlated with neurophysiological and neuroanatomical data from the literature.

\section{LITERATURE CITED}

Ades, H. W., AND J. M. BRookHaRT 1950 The central auditory pathway. J. Neurophysiol., 13 : 189-205.

ADEs, H. W., AND R. E. FELDFR 1942a The primary cortical acoustic area of the monkey and the geniculo-temporal radiation. Fed. Proc., $1: 1$. $1942 \mathrm{~b}$ The acoustic area of the monkey (Macaca mulatta). J. Neurophysiol., 5 : 49-54.

1945 The acoustic projection system: A comparative study. Ibid., 8: $463-470$.

Bailey, P., G. von Bonin, E. W. Davis, H. W. Garol and W. S. MoCuluoch 1944 Further observations on associational pathways in the brain of Macaca mulatta. J. Neuropath. Exp. Neurol., 3: 413-415.

Bailey, P., G. von Bonin, H. W. Garol and W. S. McCulloch 1943 Functional organization of temporal lobe of monkey (Macaca mulatta) and chimpanzee (Pan satyrus). J. Neurophysiol., 6: 121-128.

Baldwin, M., L. L. Frost AND C. D. Wood 1954 Investigation of the primate amygdala movements of the face and jaws. Neurology, 4: 586-598.

Barnes, W. T., H. W. MAGoun AND S. W. RANSON 1943 The ascending auditory pathway in the brain stem of the monkey. J. Comp. Neur., 79: 129-152.

Brodmann, K. 1909 Vergleichende Lokalisationslehre der Grosshirnrinde. Barth, Leipzig. 324 pp.

Chusm, J. G., O. Sugar ANd J. D. FRENCH 1948 Corticocortical connections of the cerebral cortex lying within the areuate and lunate sulei of the monkey (Macaca mulatta). J. Neuropath. Exp. Neurol., $7: 439-446$.

Crosby, E. C. 1953 Relations of brain centers to normal and abnormal eye movements in the horizontal plane. J. Comp. Neur., 99: 437-480.

Fleming, J. F., and E. C. Crosby 1955 The parietal lobe as an additional motor area. The motor effects of electrical stimulation and ablation of cortical areas 5 and 7 in monkeys. Ibid., 103: 485-512.

Frontera, J. G. 1956 Some results obtained by electrical stimulation of the cortex of the island of Reil in the brain of the monkey (Macaca mulatta). Ibid., 105: 365-394.

Hirasawa, K., S. OKano and S. Kamio 1938 Beitrag zur Kenntniss über die corticalen extrapyramidalen Fasern aus der Area temporalis superior (Area 22) beim Affen. Ztschr. f. mikr,-anat. Forsehg., 44: 74-84. 
HubER, G. C., AND S. R. Gulld 1913 Observations on the peripheral distribution of the nervus terminalis in mammalia. Anat. Rec., $7: 253-272$.

KFmp, E. H., AND G. Coppie 1936 Les voies anditives au niveau de la moelle allongée (chat). Distribution systématique des voies nerveuses acoustiques dans le mésencéphale. C. R. Soc. de Biol., 122: 1299-1301.

LICKLIDER, J. C. R., AND K. D. KRYTER 1942 Frequency-localization in the auditory cortex of the monkey. Fed. Proc., 1: 51.

LEMmeN, L. J. 1951 An anatomical and experimental study of temporal and occipital association areas. J. Comp. Neur., 95: 521-559.

MoCuLLocr, W. 1949 Mechanisms for the spread of epileptic activation of the brain. Eleetroencephalog. Clin. Neurophysiol., 1: 19-24.

Nielsen, J. M. 1946 Agnosia, Apraxia, Aphasia; Their Value in Cerebral Localization. Paul B. Hoeber, Ine., New York and London. $292 \mathrm{pp}$.

OLszewski, J. 1952 The Thalamus of Macaca mulatta. An Atlas for Use With the Stereotaxic Instrument. S. Karger, New York. 93 pp.

PeELe, T. L. 1944 Acute and ehronie parietal lobe ablations in monkeys. J. Neurophysiol., 7: 269-286.

Petr, R., L. B. Holden AND J. Jirout 1949 The efferent intercortical conneetions of the superficial cortex of the temporal lobe (Macaca mulatta). J. Neuropath. Exp. Neurol., 8: 100-103.

PoLlak, S. 1932 The main afferent fiber systems of the cerebral cortex in primates. Part II. Auditory system. Univ. of Calif. Public. in Anat. Univ. of Calif. Press, Berkeley, 2: 81-104.

Schneider, R. C., AND E. C. Crosby 1954 Stimulation of "second" motor areas in the macaque temporal lobe. Neurol., 4: 612-622.

Sugar, O., J. D. French and J. G. Chusin 1948 Corticocortical connections of the superior surface of the temporal opereulum in the monkey (Macaca mulatta). J. Neurophysiol., 11: 175-184.

SWANK, R. L., AND H. A. DavenpoR' 1935 Chlorate-osmic-formalin method for staining degenerating myelin. Stain Tech., 10:87-90.

SUNDERLand, S. 1939 The projection of the cerebral cortex on the pons and cerebellum in the macaque monkey. J. Anat., 74:201-226.

ThurLow, W. R., N. B. Gross, E. H. Kemp and K. Low 1951 Mieroelectrode studies of neural auditory activity of eat. I. Inferior colliculus. J. Neurophysiol., 14: 289-304.

TUnturi, A. R. 1944 Audiofrequency localization in the acoustic cortex of the dog. Am. J. Physiol., 141.: 397-403.

1945 Further afferent connections to the acoustic cortex of the dog. Ibid., 144: 389-394.

1946 A study on the pathway from the medial geniculate body to the acoustic cortex in the dog. Ibid., 147: $311-319$.

Walker, A. E. 1938 The Primate Thalamus. The University of Chicago Press, Chicago, Illinois. $321 \mathrm{pp}$.

WALLRR, W. H. 1934 Topographical relations of cortical lesions to thalamie nuclei in the albino rat. J. Comp. Neur., 60: 237-269.

1940 Thalamie degeneration induced by temporal lesions in the cat. J. Anat., $74: 528-536$. 
WALzL, E. M., AND C. N. Woolsey 1943 Cortical auditory areas of the monkey as determined by electrical exicitation of nerve fibers in the osseous spiral lamina and by click stimulation. Fed. Proc., 2: 52.

WARD, A. A. 1948 Anterior cingulate gyrus and personality. Res. Publ. Assn. Nerv. Ment. Dis., $2^{n}: 438-445$.

Yoshida, I. 1924 Über den Ursprung der kortikopetalen Hörbahn beim Kaninchen. Folia Anat. Japon., 2: 289-296. 


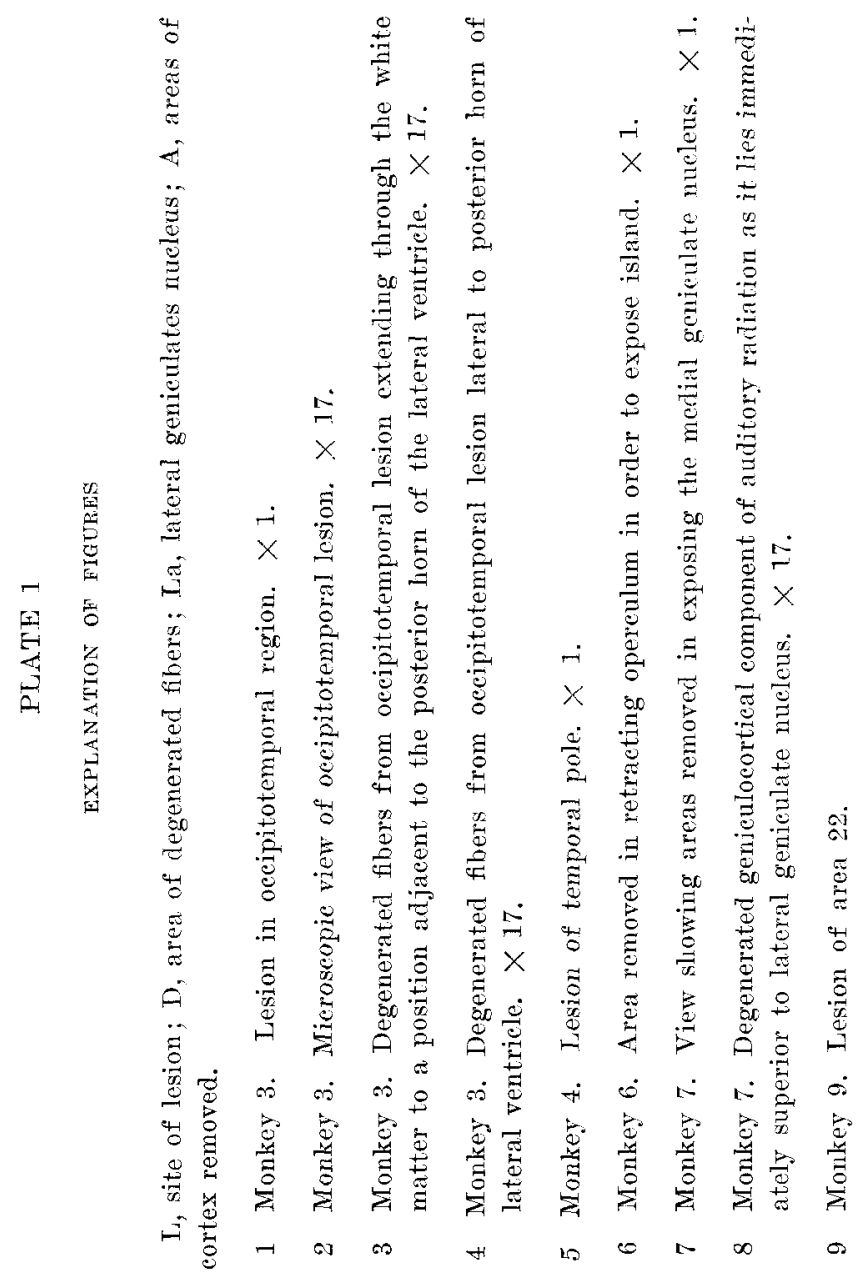



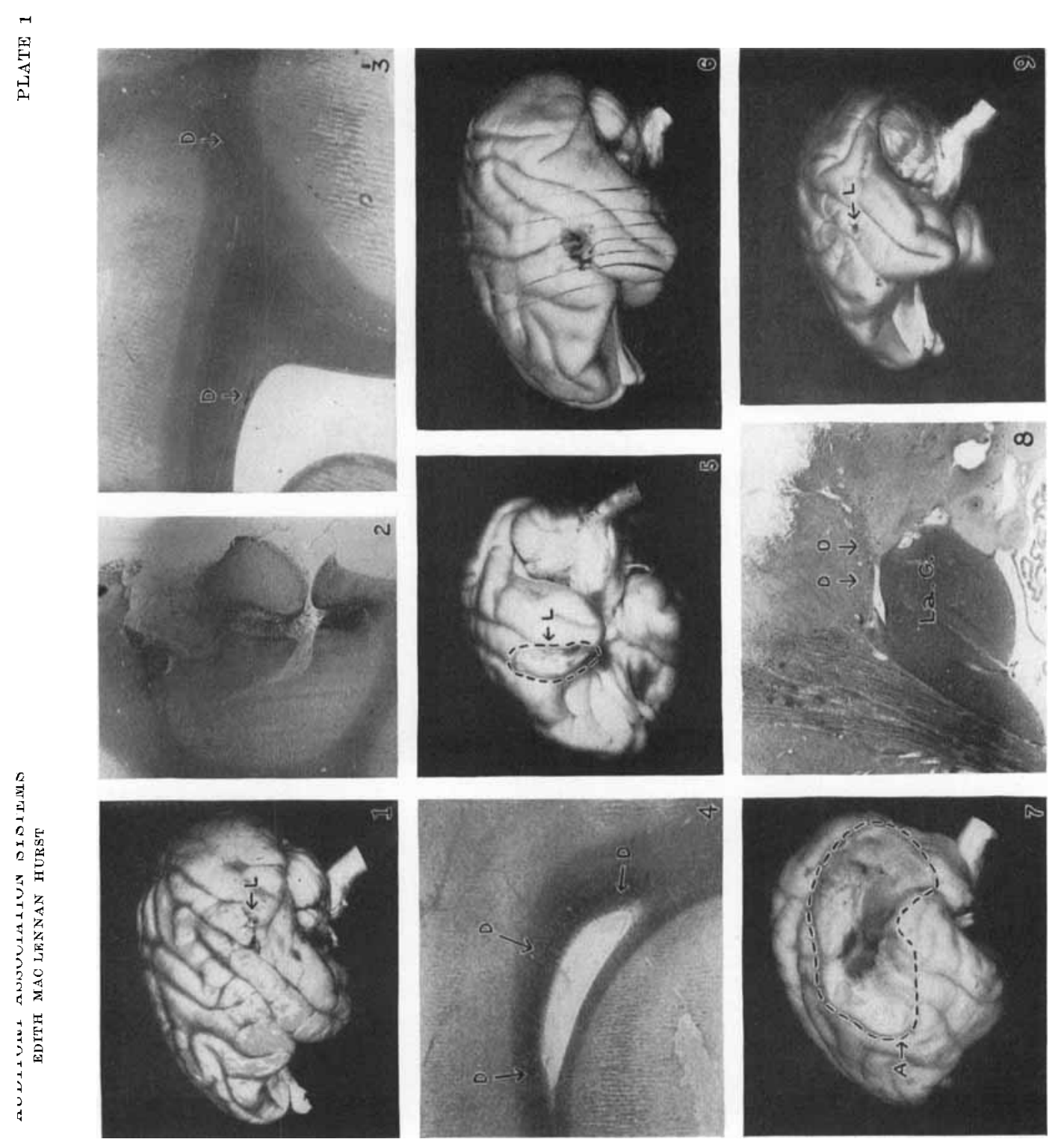